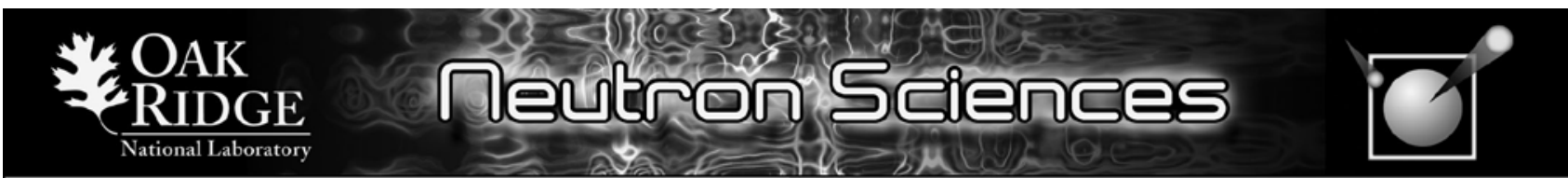

\section{Visitor Program}

Collaborative Research Opportunities in Neutron Science

- Visiting Student Thesis Research Program

- Visiting Post-doctoral Research Program

- Faculty Research Sabbaticals

The Neutron Scattering Science Division at the Oak Ridge National Laboratory (ORNL) announces new collaborative opportunities for visiting researchers. Possibilities exist for faculty sabbaticals during the summer or academic year. In addition, it is anticipated that funding will be available for short- and long-term research placements for university-based postdoctoral fellows and graduate students to pursue research using neutron scattering at ORNL. This will allow students, postdoctoral fellows, and their academic mentors to participate in exciting world-leading research in collaboration with ORNL scientific staff, using unique state-of-the-art facilites at the Spallation Neutron Source and High Flux Isotope Reactor. Additional benefits include the chance to meet and interact with many other leading scientists who visit ORNL's neutron scattering facilities to pursue their own research. The scientific areas are open to any branch of materials-based research that can use neutron scattering, including Biology, Chemistry, Engineering, and Physics.

Applications and visiting start dates will be considered on an ongoing basis, but for full consideration for visits during the summer of 2011, applications are due by December 31, 2010.

Additional details can be found at: http://neutrons.ornl.gov/crv or contact us at nsvisit@oml.gov

\section{Industrial Liaison}

The Oak Ridge National Laboratory (ORNL) invites applications for a Neutron Sciences Industrial Liaison in the Neutron Sciences Directorate. With the United States' highest-flux, reactor-based neutron source for condensed matter research (the High Flux Isotope Reactor) and the world's most intense pulsed, accelerator-based neutron source (the Spallation Neutron Source), ORNL is becoming the world's foremost center for neutron science. Research at these facilities encompasses the physical, chemical, materials, biological, and medical sciences and will provide opportunities for up to 2000 researchers each year from industry, research facilities, and universites all over the world.

The Neutron Sciences and the Technology Partnerships Directorates jointly seek candidates with outstanding records of accomplishment and demonstrated ability to build world-leading innovative programs of neutron scattering research in partnership with industrial organizations. Candidates with research experience in relevant scientific disciplines are invited to apply. The liaison is expected to build comprehensive programs that increase the awareness and use of neutron scattering techniques in applied research programs in collaboration with industrial partners. Such programs are expected to maximize the impact of ORNL research capabilities in the applied sector and link to similar capabilities in other ORNL directorates, govemment agencies, and associated universities.

For more information about this position and to apply, visit jobs.oml.gov.

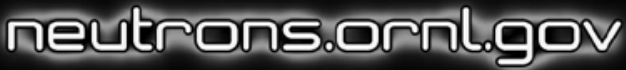

\section{RESEARCH ASSOCIATE Nanoscience}

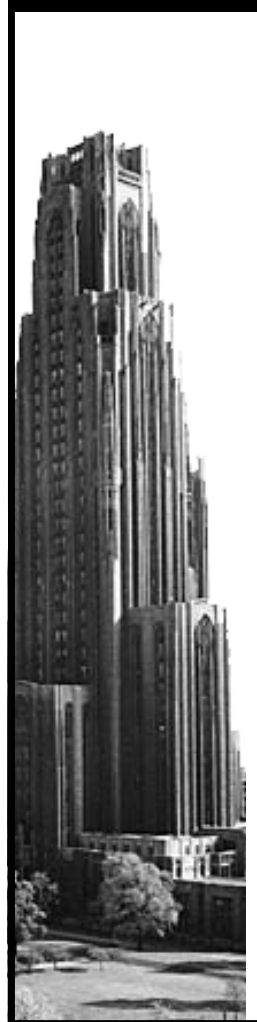

The Petersen Institute of NanoScience and Engineering (PINSE: www.nano.pitt.edu) at the University of Pittsburgh has an immediate opening for a full-time research associate (RA). The RA will be responsible for supporting the research activities relating to the nanoscale fabrication instrumentation (electron beam lithography, focused ion beam etching, dip-pen, and nanoimprint) within the Nanoscale Fabrication and Characterization Facility (NFCF). The RA will be required to maintain and operate the equipment for current and future research efforts and also to assist and train students, post-docs, and other scientists on the equipment. The ability to contribute to the related activities of NFCF in nanofabrication, process integration, and characterization is also desirable.

The successful candidate must have a PhD degree in electrical engineering, physics, materials science, chemistry, or related field; extensive knowledge and experience in materials/device processing; fabrication and instrumentation in cleanroom environment; and a strong aptitude for collaborative research in an academic environment. Excellent interpersonal communication and writing skills also are important. Please send a cover letter and a $\mathrm{CV}$ with contact information for three references by January 31, 2011 to:

Theresa Costanzo, 348 Benedum, University of Pittsburgh, Pittsburgh, PA 15261 (costanzo@engr.pitt.edu).

\section{Faculty Positions}

Mechanical Engineering

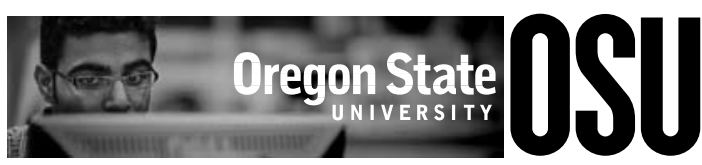

The School of Mechanical, Industrial, and Manufacturing Engineering at Oregon State University invites applications for multiple full-time (1.0 FTE), 9-month, tenure-track faculty positions in Mechanical Engineering at the Assistant or Associate Professor ranks.

Applicants must have earned $\mathrm{PhD}$ degree in Mechanical Engineering or related area by the start date of employment. Teaching responsibilities include delivering undergraduate and graduate courses in Mechanical Engineering, Industrial Engineering, and/or Material Science. Preference will be given to candidates with strong research and teaching experience in the areas of design, mechanics, dynamics, controls, and materials science. Of particular interest are individuals with research interests in smart materials, smart structures, system health monitoring, advanced control systems, robotics, computational and experimental mechanics, and complex systems/product design. For detailed announcement, see http://mime.oregonstate.edu/jobs/.

To view posting and apply, go to http://oregonstate.edu/jobs/; see posting \#0006289. To ensure full consideration, applications must be received by December 15, 2010. Applications will continue to be accepted after the for-full consideration date, until the position is filled. The closing date is subject to change without notice to applicants. Apply online with a letter of interest; vita; a two-page statement of research interests; a one-page statement of teaching interests; and names and contact information for four references.

Oregon State University is an Affirmative Action/Equal Opportunity Employer. 
ER DES $N$ 115.01.XX

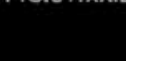

\section{Department of Engineering Physics}

The Department of Engineering Physics of Polytechnique Montréal, one of the premier Canadian institutions for undergraduate and graduate education in engineering, is seeking to fill two positions.

\section{ASSOCIATE/ASSISTANT PROFESSORS}

Department of Chemical \& Biological Engineering

The Department of Chemical \& Biological Engineering at the University of Alabama seeks applications and nominations for four Associate/Assistant Professor positions, with a start date as early as January 2011. We are seeking candidates who will develop a nationally competitive research program with a strong emphasis on fields related to biological engineering, environmental engineering, or energy. It is expected that the successful candidates will work with interdisciplinary colleagues in UA's biological sciences, chemistry, and engineering departments in developing and sustaining their research programs.

The successful candidates must have a balanced perspective on research and instruction. Teaching at both graduate and undergraduate levels is essential. Applicants must hold a doctoral degree in chemical engineering or a closely related field.

UA's Chemical and Biological Engineering Department offers $\mathrm{BS}, \mathrm{MS}$, and $\mathrm{PhD}$ degrees, and currently has an enrollment of over 400 undergraduate students, 23 graduate students, and 13 faculty. Sponsored research projects currently exceed \$2 million. The department plays a leading role in the College of Engineering's research and educational missions. For more information on the department, see our website at che.eng.ua.edu.

Interested persons should submit a curriculum vito and a separate document including a cover letter description of research plans, a statement of teaching philosophy, and the names of three references. These two documents should be uploaded by accessing facultyjobs.ua.edu.

The applications may be submitted to one or more of the following postings:

1. Biological Engineering and Other Research Areas: Organization 214221-Chemical and Biological Engineering, Requisition \#0804292

2. Environmental Engineering Research Organization 214221-Chemical and Biological Engineering, Requisition \#0804355

3. Energy Research: Organization 200301-

Materials for Information Technology, Requisition \#0803403

Review of applications will begin immediately and will continue until the positions are filled.
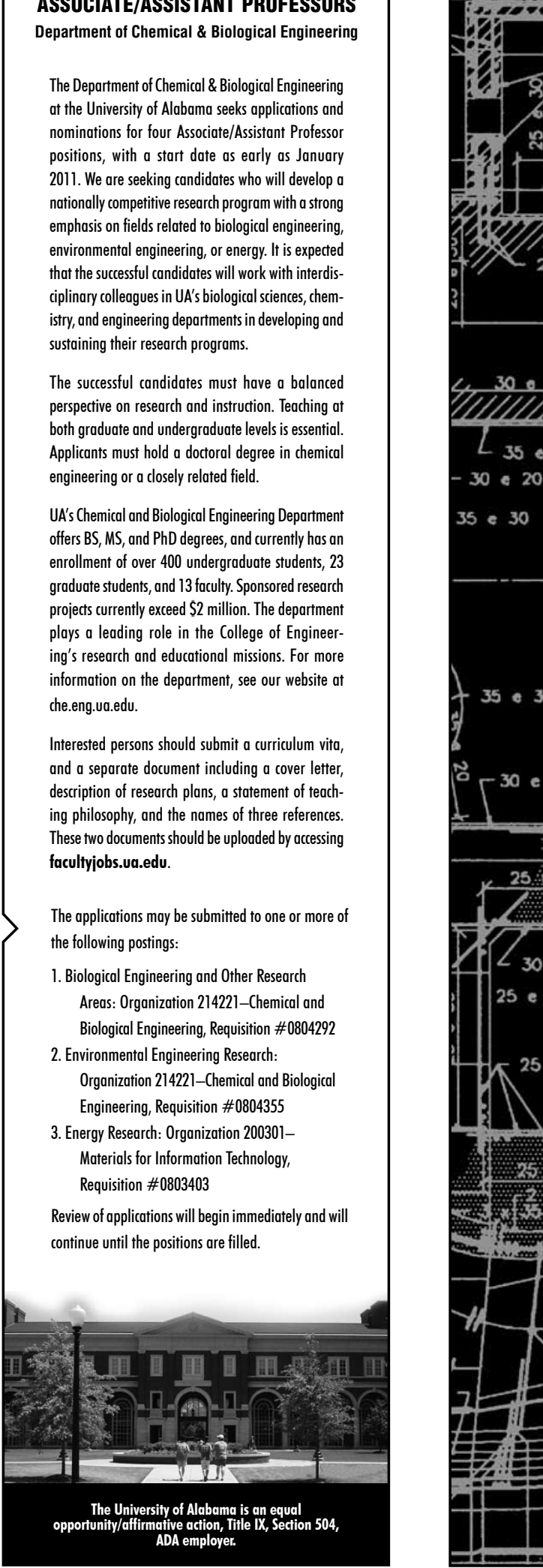

$30 \div 20$
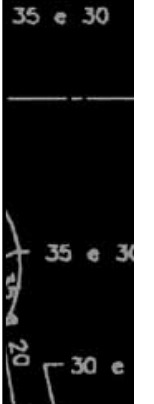

\section{Canada Research Chair - Tier II}

We are seeking to fill a Canada Research Chair (Tier II) position. The department will consider outstanding candidates in any area of engineering physics. Applications in quantum and non linear optics, biophotonics, microfabrication and microsystems, and nanotechnology are particularly welcome.

This tenure-track appointment will be at the level of Assistant or Associate professor. Candidates must hold a Ph.D. degree (received within the last 10 years) in Engineering Physics, Physics, or a related field. The successfu candidate must be a member of the Ordre des ingénieurs du Québec (OIQ), or take the necessary measures to become a member during his/her first contract. Applicants must demonstrate a successful record of research. The successful candidate will be expected to teach, in French, both undergraduate and graduate courses, to supervise graduate students, and to establish a strong externally funded research program. Canada Research Chairs are subject to review and approval by the CRC Secretariat. Further details on the program can be viewed at www.chairs.gc.ca.

\section{Faculty Position}

We are seeking to fill a tenure-track faculty position. Applications in the areas of nuclear reactor engineering (especially thermal-hydraulics), microsystems and microfabrication, quantum optics and biophotonics are particularly welcome.

Candidates must hold a Ph.D. degree in Engineering Physics, Nuclear Engineering, Physics, or a related field. The successful candidate must be a member of the Ordre des ingénieurs du Québec (OIQ), or take the necessary measures to become a member during his/her first contract. The successful candidate will be expected to teach, in French, both undergraduate and graduate courses, and to supervise graduate students. Applicants must have the ability to establish a strong research program.

The candidates selected will become part of a team of professors who have recognized expertise in condensed matter physics, photonics, and nuclear engineering. Members of the department are also involved in several well-established research networks. See our website for more details: www.polymtl.ca/phys.

To apply

Candidates should submit an application package that consists of a curriculum vitae, a statement of teaching goals and research priorities, records of teaching effectiveness, official records of their diplomas, the names of three references, examples of work relevant to the position and reprints of recent publications. All application material should be sent as soon as possible to:

\section{Patrick Desjardins \\ Professor and Head \\ Department of Engineering Physics \\ École Polytechnique de Montréal \\ P.O. Box 6079, Station Centre-ville \\ Montréal, Québec H3C 3A7 \\ Canada}

For additional information and to indicate your intention to apply, please contact: postes@phys.polymtl.ca.

Examination of applications will begin on January $21^{\text {st }}, 2011$, and will continue until the positions are filled. All qualified persons are encouraged to apply. However, Canadians and permanent residents will be given priority.

\section{(1)}

ÉCOLE POLYTECHNIQUE $M O N T R E$ A
Only candidates selected for interviews will receive a written response. In accordance with Canadian immigration requirements, Canadians and permanent residents will be given priority. 


\section{FACULTY POSITION}

School of Civil and

Environmental Engineering

Cornell University, School of Civil and Environmental Engineering, announces a tenure-track faculty position in structural engineering starting in Fall 2011. At Cornell, structural engineering is viewed broadly, encompassing materials and structures across scales where well understood physical laws apply. Thus we are seeking a well prepared candidate with a passion for applying fundamental scientific principles, cast within the framework of solid and structural mechanics and the mathematics of uncertainty, to enable improvements in understanding and design of complex structural systems across a range of materials.

In this spirit, a candidate is sought whose principal application interests are:

1. Uncertainty quantification: Development of multiscale and multiphysics probabilistic models for both mechanical properties of structural systems and actions on these systems, and calibration of these models to experimental data and any other available information.

2. Probabilistic mechanics: Formulation of stochastic equations capable of capturing input system uncertainty that is present in most structural mechanics problems, solution of these equations, and construction of metrics for assessing system performance.

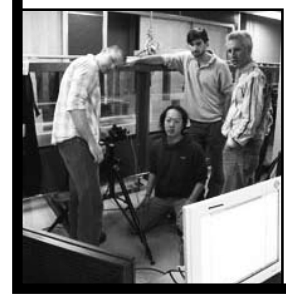

Application areas of interests include smart and multifunctional materials, earthquake engineering, risk and reliability, hybrid physical/computational evaluation of materials and structures, sensing and structural health monitoring, and novel structural systems and materials supporting sustainable energy systems.
The successful candidate for this position is expected to conduct a vigorous funded research program seeking innovative solution methodologies to challenging structures problems. The candidate will also be expected to rapidly become an effective teacher in both graduate and undergraduate courses in solid and structural mechanics, as well as specialty areas. Candidates must have a PhD degree in engineering or an allied field within the physical sciences. Appointment at the rank of Assistant Professor is anticipated, but applications from candidates from all levels are welcomed. Applications will be held in strict confidence.

The School of Civil and Environmental Engineering and the College of Engineering at Cornell embrace diversity and seek candidates who will create a climate that attracts students of all races, nationalities and genders. We strongly encourage women and underrepresented minorities to apply.

Cornell University seeks to meet the needs of dual career couples, has a Dual Career program, and is a member of the Upstate New York Higher Education Recruitment Consortium to assist with dual career searches. Visit http://www.unyherc.org/home/index.cfm?site_id=671 to see positions available in higher education in the upstate New York area.

Applicants should submit a curriculum vita, a research statement, a teaching statement, an official graduate transcript, one to three publications, and complete contact information for at least three references. Application materials must be submitted on-line at http://academicjobsonline.org/ajo/Cornell/CEE/505. Review of applications will begin immediately and continue until the position is filled.

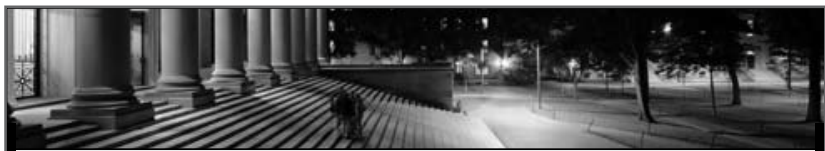

ASSISTANT PROFESSOR IN FLUID MECHANICS HARVARD UNIVERSITY School of Engineering and Applied Sciences

The Harvard School of Engineering and Applied Sciences (HSEAS) seeks applicants for an opening at the level of tenure-track assistant professor in fluid mechanics. The ideal candidate will have high expertise in fluid mechanics and will also have a demonstrated commitment to significant and innovative applications in engineering.

The position requires a PhD degree in engineering or a closely related field, the ability to develop a leading research program, and enthusiasm for teaching both graduate and undergraduate courses in engineering. Successful candidates will work with HSEAS faculty to develop a curriculum for our ABET-accredited engineering program.

Harvard University is committed to increasing its investment in engineering, as exemplified by the recent reorganization of the engineering program into the School of Engineering and Applied Sciences. New construction of facilities and a substantial increase in the size of faculty are in progress. HSEAS benefits from outstanding undergraduate and graduate students and a collaborative research environment without departmental boundaries.

Applicants should send a cover letter, $\mathrm{CV}$, a statement of teaching interests, a statement of research plans, copies of three publications, and names and contact information for at least three references. These documents should be submitted as a single pdf attachment to fluidmechsearch@ seas.harvard.edu.

We encourage applications before 31 December 2010, but will continue to review new applications until the positions are filled.

Harvard University is an Equal Opportunity/Affirmative Action employer and applications from women and underrepresented minorities are strongly encouraged.

\section{FACULTY POSITION}

\section{In Materials SCIENCE AND ENGINEering, THE UNIVERSITY OF MICHIGAN}

The Department of Materials Science and Engineering (MSE), College of Engineering, University of Michigan, invites outstanding applicants for a tenure-track faculty position in the area of energy storage. Emphasis will be placed on applicants with a record of research accomplishment in the area of energy storage. Each applicant must hold a Ph.D. degree in MSE, or a related field, and should be qualified, and willing, to teach undergraduate and graduate courses within the field. We seek candidates who will provide inspiration and leadership in research and contribute actively to teaching, and are especially interested in candidates who can contribute, through their research, teaching and/or service, to the diversity and excellence of the academic community. The University of Michigan is responsive to the needs of dual career families.

Candidates should submit a cover letter, resume, research and teaching plans, publication list, and the names of four references to our website at http://www.mse.engin.umich.edu/facsearch/ energystorage. The deadline for applications is January 31, 2011.

Contact information:

mse-energy-storage-faculty-search@umich.edu

Faculty Search Chair
Department of Materials Science and Engineering The University of Michigan

2300 Hayward Street, Ann Arbor, MI 48109-2136

\section{MichiganEngineering}


Max-Planck-Institut für

Eisenforschung $\mathrm{GmbH}$

Düsseldorf (Germany)

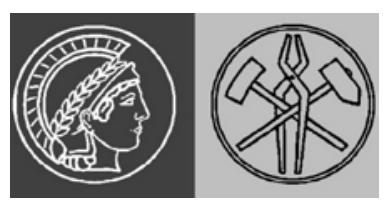

We announce an opening for the position of a

\section{Max Planck Director}

The Max-Planck-Institut (www.mpie.de) is devoted to fundamental research on complex materials with a strong focus on metals, composites, nanostructured alloys, semiconductors, and functional surfaces. Applications of interest are in the fields of mobility, health, energy, synthesis, and alloy design. We are looking for candidates with an interdisciplinary research profile in

\section{Materials Science and Engineering}

The successful candidate will be appointed as head of a department at the full professor level (W3) and Scientific Member of the Max Planck Society. We provide a competitive research environment at highest international level with strong facets in theory, experiment, characterization, and synthesis. We are interested in a colleague willing to strongly cooperate with the existing departments. Experts in the field at a junior and senior research level and with strong scientific record are encouraged to apply.

We are an equal-opportunity employer. Applications should be sent before 31. January 2011 via post or email (as pdf) to:

\section{Max-Planck-Institut für Eisenforschung $\mathrm{GmbH}$ Geschäftsführung \\ Max-Planck-Str. 1 • 40237 Düsseldorf director-eifo@mpie.de}

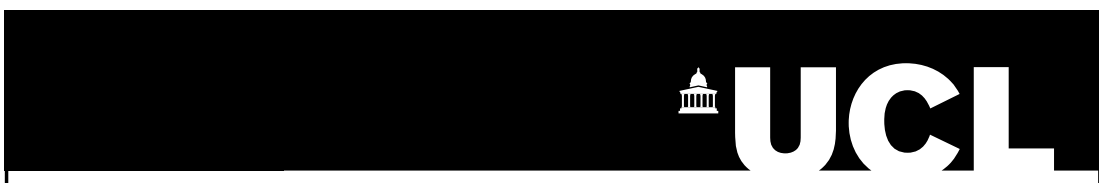

UCL London Centre for Nanotechnology

\section{Research Associate}

The appointment will be full time on UCL Grade 7. The salary range will be $£ 31,778-£ 38,441$ pa, inclusive of London Allowance

The London Centre for Nanotechnology (LCN) is seeking to appoint a postdoctoral researcher to establish molecular beam epitaxy (MBE) of oxide nanowires and oxide nanowire heterostructures.

A new research MBE system is on order and is due for delivery to the London Centre for Nanotechnology in Spring 2011. The postholder will be involved in the commissioning of this $\mathrm{MBE}$ system and in developing growth protocols for $\mathrm{ZnO}$ thin films and $\mathrm{ZnO}$ nanowires. The ultimate goal of the project is to grow heterostructure nanowires (including $\mathrm{ZnO}-\mathrm{ZnMnO}$ and $\mathrm{ZnO}-\mathrm{ZnMgO}$ ).

The post is funded by a major EPSRC grant held by Dr. Paul Warburton. The appointment is initially for a period of 30 months.

The successful applicant will have a higher degree qualification $(\mathrm{PhD})$ or equivalent in experimental physics or experimental materials science or experimental electrical engineering. $\mathrm{He} / \mathrm{she}$ will also have first-hand experience with ultra-high vacuum equipment, a track record of publication in high-impact scientific journals and a demonstrated ability for innovation and original research.

For further details about the vacancy and how to apply online please go to http://www.ucl.ac.uk/hr/jobs/ and search on Reference Number: 1165623.

Informal enquiries may be made to Dr. Paul Warburton (p.warburton@ucl.ac.uk). If you are unable to apply online please contact Ms. Denise Ottley, London Centre for Nanotechnology, 17-19

Gordon Street, London WC1H OAH or email: d.ottley@ucl.ac.uk

Closing date: 20 th December 2010 by $5.00 \mathrm{pm}$

UCL Taking Action for Equality

\section{universitr of \\ Cincinnati}

\section{Postdoctoral Fellow Carbon Nanotube Synthesis and Applications}

The University of Cincinnati, Cincinnati, Ohio, is looking to hire a postdoctoral fellow for a period of three years with a strong background in the field of Chemical Vapor Deposition (CVD), processing of Carbon Nanotubes (CNT), and related instrumentation. Experience in growing spin-able carbon nanotube arrays and in manufacturing CNT thread and yarn is a plus. This position requires knowledge in the field of characterization and application of carbon nanotubes (CNT). Special skills and experience are expected from the candidate in this field. In addition, assembling a new CVD facility and improvement of the existing one will be part of the long-term assignment related to this position. For characterization of CNT arrays, knowledge in using modern analytical tools such as XRD, ESEM, HRTEM, AFM, Raman Spectroscopy, TGA, and XPS is also expected. Finally, development initiatives for advanced applications of CNT arrays and yarns in nanocomposite and electronic and biomedical devices will be also part of the duties of the postdoctoral fellow.

The employee is expected to participate in selecting, purchasing, installing, and operating the facilities and instrumentations that will be purchased. In addition, he or she will supervise graduate students, participate in writing of scientific proposals and publish papers in referred journals. The Nanoworld Lab at UC is one of the leading research establishments in the field of CNT synthesis and applications. More information can be found at http://www.min.uc.edu/nanoworldsmart/.

The position will be available starting January 31, 2011, and will include full benefits from the university. Submit applications to https://www.jobsatuc.com, Position 210UC1907.

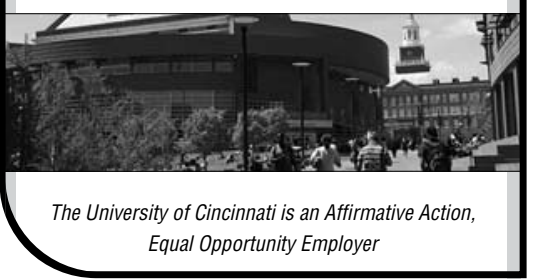




\section{Assistant Professor or Associate Professor}

Department of Mechanical and Manufacturing Engineering Faculty of Engineering

Located in the thriving, multicultural city of Winnipeg, the University of Manitoba offers students and faculty a vibrant learning community, exceptional facilities and the chance to explore ideas, challenge assumptions and turn theory into reality. Our researchers are among the best in the world, finding new ways to protect the environment, improve human health, advance technology and strengthen communities in Canada and beyond. With more than 30,000 students, faculty, and staff, and over 90 degree programs, the University of Manitoba plays a key role in the social, cultural, and economic well-being of our community and our world.

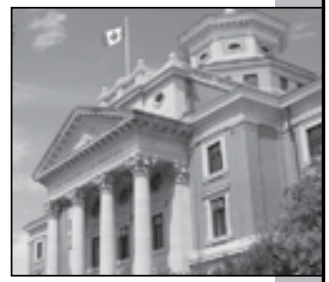

A tenure-track faculty position at the Assistant Professor or Associate Professor level is available in the area of Materials in the Department of Mechanical and Manufacturing Engineering at the University of Manitoba. The successful candidate will demonstrate expertise and a strong academic record in Materials Science with strong emphasis on new materials and on computational Materials Science, with the primary hiring criteria being the candidate's background in Materials Engineering with proven excellent numerical simulation and modeling skills applicable to either or combination of processing, microstructure and properties of advanced bulk materials, such as, nano-structured materials, hybrid materials and metallic glasses. The starting date for this position is July 2011. Salary will be commensurate with qualifications and experience.

Candidates must have a Ph.D. degree in a field related to the required areas of specialization. The duties of the successful candidate will include undergraduate and graduate teaching, supervision of graduate students and the development of an active, externally-funded research program. The ability to interact with Manitoba and Canadian industries would be an asset. As a condition of employment, the successful candidate will be expected to apply with the Association of Professional Engineers and Geoscientists of Manitoba (APEGM) within one year of the start date.

The Department of Mechanical and Manufacturing Engineering is responsible for an accredited Mechanical Engineering undergraduate program and options in Aerospace Engineering and Manufacturing Engineering. The Department is very active in graduate teaching and research at the M.Eng., M.Sc. and Ph.D. levels. Currently there is a Tier-II Canada Research Chair in Solid Mechanics and a NSERC/Manitoba Hydro Alternate Energy Industrial Research Chair, and there is an ongoing search for a Tier II Canada Research Chair in Biomedical Materials Engineering. The Department presently has 27 academic staff, 14 support staff, several post-doctoral fellows, research associates and visiting scholars, as well as approximately 120 graduate students and 380 undergraduate students.

Additional information on the Department can be found at our website

http://umanitoba.ca/faculties/engineering/departments/mechanical/index.html

Winnipeg is a mature city of some 700,000 people with rich recreational and cultural opportunities. It combines the amenities of urban life with easy access to the countryside and to northern lakes and forests. Housing prices are low by North American standards. Additional information can be found at: http://www.city.winnipeg.mb.ca/ and http://www.gov.mb.ca/

The review of applications will begin on December 1, 2010, and will continue until the position is filled. Applications should quote Search \#12118 and include a curriculum vitae, a one-page statement of research and teaching goals as well as contact information for at least three referees. Please submit all materials to: Professor D. Kuhn, Chair of the Search Committee, Department of Mechanical and Manufacturing Engineering, University of Manitoba, Winnipeg, Manitoba, Canada R3T 5V6, www.umanitoba.ca

All e-mail enquiries should be sent to nabess@cc.umanitoba.ca to the attention of Prof. D. Kuhn.

The University of Manitoba encourages applications from qualified women and men, including members of visible minorities, Aboriginal peoples, and persons with disabilities. All qualified candidates are encouraged to apply; however, Canadians and permanent residents will be given priority.

Application materials, including cover letter, curriculum vitaes, and letters of reference, will be handled in accordance with the protection of privacy provisions of "The Freedom of Information and Protection of Privacy Act" (Manitoba) and will be provided to participating members of the search process.

For more information on this opportunity, please visit umanitoba.ca/employment

One university. Many futures.
UNIVERS ITY OF MANITOBA
ASSISTANT PROFESSOR Materials Science \& Engineering

The interdisciplinary Materials Science and Engineering program at the University of Colorado (mse.colorado.edu) seeks to hire exceptional candidates as assistant professors, with higher levels also considered. This program offers tenure-track appointments in science and engineering departments across the campus to candidates with interests in materials research. Candidates with interests in all materials research areas will be considered. Applicants should go to www.jobsatcu.com (Posting \#811675) for information on submitting their applications. Review of applications will begin in December 2010. The University of Colorado at Boulder conducts background checks for all final applicants.

The University of Colorado is committed to diversity and equality in education and employment.

\section{RESEARCH SCIENTIST \\ Golisano Institute for Sustainability (GIS)} NanoPower Research Labs (NPRL)

Primary responsibilities include work related to the development of integrated power supplies based on inorganic phosphors and photovoltaic power generation sources. A PhD degree in Physics, Chemistry, Electrical Engineering, Materials Science and Engineering, Nuclear Engineering, or a related field is required. U.S. citizenship required.

Please visit our website at http://careers.rit.edu/ to view the full job description, job requirements and to apply. IRC \# IRC42735.
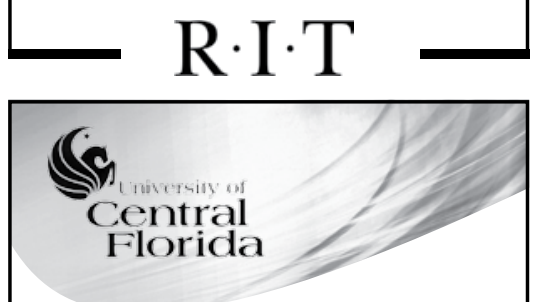

\section{Graduate Student Assistantships}

Materials Science and Engineering

The University of Central Florida (UCF) is seeking exceptional students to pursue graduate studies in Materials Science and Engineering (MSE) at the Doctoral level. Assistantship awardees will receive financial support consisting of tuition remission each year of their studies, individual student health insurance coverage, and a stipend of $\$ 30,000$ for the first year, with a minimum stipend of $\$ 25,000$ in subsequent years, dependent on performance. During their first year, awardees will have the opportunity to gain experience in several laboratories within the Advanced Materials Processing and Analysis Center and the NanoScience Technology Center at UCF prior to joining a center faculty's research group. For further information contact the MSE program coordinator (krcoffey@mail.uc.edu) or visit http://www.ampac.uff.edu.

All applicants must complete the UCF online application at http://www.admissions.graduate.uct.edu/ by January 15, 2011 to be considered for Fall 2011 admission and the MSE Assistantship award.

UCF is an Affirmative Action/Equal Opportunity Employer. Minorities and women are encouraged to apply. 


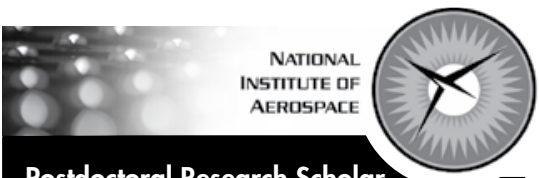

Postdoctoral Research Scholar

National Institute of Aerospace (NIA) is seeking a postdoctoral Research Scholar to work in the area of electronic materials research and specifically expitaxial growth of new bandgap materials. Successful candidate will support effort to strengthen on-going research on epitaxial growth of thick films, with special emphasis on high charge mobility of $\mathrm{SiGe}$ and related quantum-well structure.

This position will provide a unique opportunity to perform independent research within an established team and to use well-equipped laboratories (sputtering deposition, AFM, 4-circle XRD, TEM, SEM, EBSD, SIMS, etc.), as well as to collaborate with researchers in the Nano-Bio Electronic Advanced Materials Group, Advanced Material, and Processing Branch at NASA Langley Research Center in Hampton, VA. PhD degree or equivalent in condensed matter physics, materials science, electrical engineering, or related field, and an understanding of issues related to $\mathrm{mi}$ crofabrication, thermoelectric materials, ferroelectrics, and correlated-electron materials. Experience in the synthesis of epitaxial layers is desired, and familiarity with common techniques of materials characterization.

Visit us at www.nianet.org to apply and for more information.

NIA is an equal opportunity/affirmative action employer.

Assistant Professor - Materials Engineering University of California, Merced

The School of Engineering at the University of California at Merced invites applications for an Assistant Professor faculty position in the area of energy materials including solar, battery, fuel cell, and energy-harvesting applications beginning July 1, 2011. Candidates with proven expertise in nanomaterials synthesis for energy generation, conversion, storage, or delivery are particularly encouraged to apply. The deadline for submission of application is January 15, 2011.

To apply, or for more information, please visit our website at http://jobs.ucmerced.edu/n/academic/ position.jsf?positionld $=2957$.

$$
\text { AA/EOE. }
$$

NEI Corporation Scientist Electrochemistry

NEI Corporation, Somerset, New Jersey, USA, (www.neicorporation. com) is seeking a highly technical individual with experience in Li-ion battery systems. The individual's responsibilities include initiating and managing industrial joint development programs and contract research in the area of Li-ion battery components, including cathode and anode materials and electrolytes.

A strong background in electrochemistry and solid state chemistry of electrode materials, thorough understanding of electrochemical phenomena in Li-ion batteries, and hands-on experience with cell fabrication and assembly is required. $\mathrm{PhD}$ or MS degree with two to five years experience in the chemical or materials industry is preferred. This full-time position is open ONLY for Citizens or Permanent Residents of USA. Please send resume to HumanResources@neicorporation.com.
UMASS

AMHERST

\section{Faculty Position in Mechanical and Industrial Engineering}

The Department of Mechanical and Industrial Engineering (MIE) at the University of Massachusetts Amherst invites applications for a tenure-track position in the area of Materials Science and Engineering. The appointment is at the rank of assistant or associate professor. Faculty members are expected to teach both undergraduate and graduate courses, supervise graduate students, produce highquality scholarly publications, and develop a nationally recognized program of sponsored research. Applicants specializing in energy-related materials, nanomaterials, and biomaterials are a priority although all materials related areas will be considered. In addition, the new faculty will participate in the development of new graduate programs in Materials Engineering within the College of Engineering.

The Department of Mechanical and Industrial Engineering has 24 full-time faculty members, close to 100 graduate students, and over 500 undergraduates. Research expenditures exceeded $\$ 4.7 \mathrm{M}$ in the last fiscal year. Faculty members in the College of Engineering with materials research interests/programs participate in various research activities across campus, with themes in energy (Center on PolymerBased Materials for Harvesting Solar Energy, a DOE Energy Frontier Research Center, Institute for Massachusetts Biofuels Research, Center for Energy Efficiency and Renewable Energy, Wind Energy Center), in nanotechnology (NSF Center for Hierarchical Manufacturing), in bioengineering (Institute for Cellular Engineering), and in the NSF Materials Research Science and Engineering Center.

The University of Massachusetts is situated 90 miles west of Boston in the vicinity of four liberal arts colleges offering exceptional and diverse cultural and recreational opportunities.

Applicants must have a PhD in mechanical engineering, materials science, or closely related field (degree by September, 2011). Candidates should provide the following in their application package: 1) Statement of interest, teaching and research qualifications, description of research goals, and a discussion of how the candidate's experience would add to existing departmental and University strengths. 2) Current curriculum vitae. 3) Representative recent original research articles.

4) Full contact information for at least four references.

Applications are strongly preferred via email in single pdf file: mie_materials@ecs.umass.edu. Applications can also be sent to: University of Massachusetts Amherst, MIE Materials Search Committee, ELab I Building, 160 Governors Drive, Amherst, MA 01003-9265. Review of applications will begin on November 22, 2010 and continue until a suitable candidate is identified.

The University of Massachusetts is an Affirmative Action/Equal Opportunity Employer. The Department, College, and University have a strong commitment to diversity. Women and members of minority groups are encouraged to apply.

\section{Faculty Position in Materials Science \& Engineering}

Cornell University, located in Ithaca, New York, is an inclusive, dynamic and innovative Ivy League university and New York's land-grant institution. Its staff, faculty, and students impart an uncommon sense of larger purpose and contribute creative ideas and best practices to further the university's mission of teaching, research, and outreach.

The Department of Materials Science and Engineering at Cornell University is soliciting applications for a tenure track faculty position. Exceptional candidates are sought, particularly those who will dramatically enhance our program in the strategic research area of energy production and storage (e.g., photocatalysis, photovoltaics, thermoelectrics, phononics, batteries, and supercapacitors). More information on Cornell MS\&E's strategic research focus is available at: http://mse.cornell.edu.

Candidates are expected to currently have or to develop an internationally recognized program of research and teaching in materials science and engineering. Considerable institutional resources are available for the support of the successful applicant's research program and a competitive start-up package can be expected. The successful candidate can expect to benefit from associations with Cornell's many interdisciplinary research centers, facilities, and initiatives, which include a number of national resources. The successful candidate will be expected to excel in the teaching of materials science and engineering and to mentor students at both the undergraduate and graduate levels. Applicants at all levels will be considered for this position.

The Department of Materials Science and Engineering and the College of Engineering at Cornell embrace diversity and seek candidates who will create a climate that attracts students of all races, nationalities and genders. Women and under-represented minorities are strongly encouraged to apply.

Applications, including a resume, a statement on teaching and research interests, copies of publications or preprints, and names of several references, should be submitted online at: http://fast.mse.cornell.edu

Applications will be reviewed starting January 1, 2011 and will be accepted until this position is filled.

http://mse.cornell.edu

Cornell University

Cornell University is an affirmative action

equal opportunity employer and educator. 


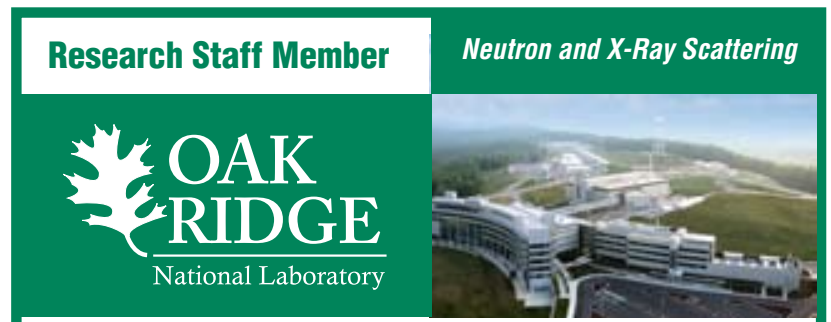

The X-Ray and Neutron Scattering and Microscopy Group in the Materials Science and Technology Division at Oak Ridge National Laboratory (www.ornl.gov) is seeking a mid-career to senior level materials scientist with a specialty in the area of Neutron and/or X-Ray Scattering basic energy sciences research. Applications are invited from candidates with demonstrated track records for conceiving and developing innovative forefront materials research programs leading to advances in fundamental understanding of condensed matter science, materials physics, nanostructures, or other energy-related research areas. The successful candidate will benefit from interactions with the diverse experimental and theoretical materials research programs at ORNL and from the forefront ORNL research capabilities, including the Spallation Neutron Source, the High Flux Isotope Reactor, the National Center for Computational Science, the Center for Nanophase Materials Sciences, and state-of-the art electron microscopy facilities.

The position requires a PhD degree in physics, materials science, applied physics, chemistry, or a closely related science and engineering discipline. A minimum of five years experience and a preexisting scientific reputation in the fields of neutron or X-ray diffraction is a requirement. Excellent written and oral presentation skills are essential. Experience in leading and developing technical programs will also be an important asset. For further consideration and to review full job description, please visit http://jobs. ornl.gov/, click view open positions, type NC50245788 in the key word search field, click start.

Oak Ridge National Laboratory is an Equal Opportunity Employer.

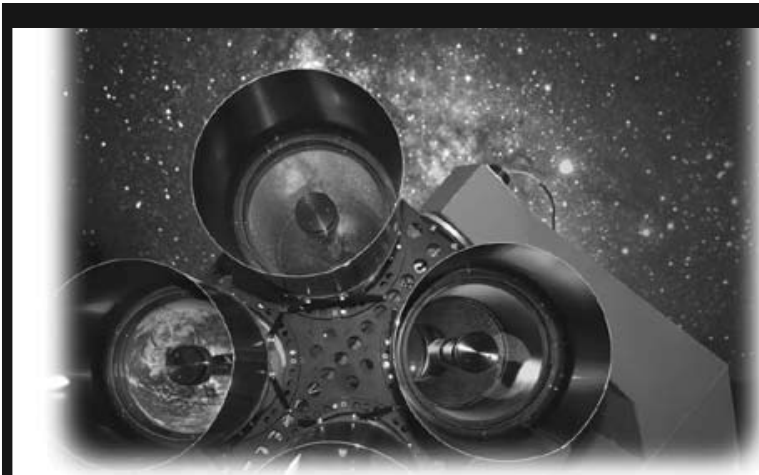

Los Alamos National Laboratory - a premier national security research institution - has a great post-doctoral research opportunity in computational materials science.

\section{POST-DOCTORAL RESEARCH ASSOCIATE}

Working with the Corrosion and Environmental Effects team, you will develop and apply atomistic modeling methods for simulating processes that occur on the surfaces of metals, including catalysis and corrosion via dissolution and oxidation.

Best candidates have a Ph.D. in Physics, Chemistry or Materials Science and the ability to apply their expertise via density functional theory or atomistic techniques. Your interest in gaining insights for otherwise inaccessible interfacial phenomena will be important.

Apply online at www.lanl.gov/jobs and include job number 220566

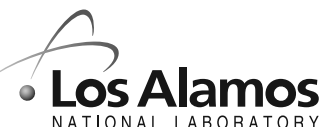

Www.lanl.gov/jobs

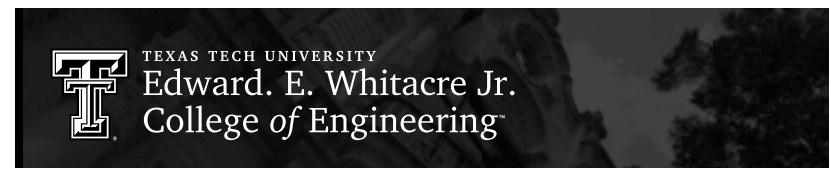

\section{The Maddox Chairs in Energy at Texas Tech University}

The Edward E. Whitacre Jr. College of Engineering at Texas Tech University is committed to leveraging these two exceptionally large endowed chairs at over \$7 million each, to become one of the nation's leaders in finding solutions to the world's energy challenges. The college is seeking world-class research

Donovan Maddox Distinguished Engineering Chair in Solar Energy Jack Maddox Distinguished Engineering Chair in Sustainable Energy

Candidates are expected to have an international reputation in the fields of solar energy or energy sciences and engineering as evidenced by publications, citations, and peer recognition. In addition, a record of acquiring external resources to support research, team building, and mentoring of associates and graduate and undergraduate students is necessary.

The successful candidates will set the tone, vision, and path in order to build an internationally recognized program at Texas Tech University in solar and sustainable energy research. The appointments will be as a full professor in the Whitacre College of Engineering.

The holders of each of the Maddox Chairs will be expected to not only bring his or her own research activities to the Whitacre College of Engineering, but also to build a collaborative community of scholars at Texas Tech to build a world-class research program.

Screening will begin upon the receipt of applications and will continue until the position is filled. Candidate names will not be made public until the final stages of the search.

Curriculum vitae and the names and contact information of at least four references should

be submitted at www.coe.ttu.edu/maddox. To nominate a colleague for these chairs, visit www.coe.ttu.edu/maddox. Nominations can be made anonymously.

Questions about the Jack Maddox or Donovan Maddox Chairs should be directed to: Jack Maddox and Donovan Maddox Search Committees

Texas Tech University | Whit cre College of Engineering

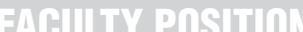

\section{School of Engineering}

Brown University established a School of Engineering on July 1, 2010 and is beginning a major hiring initiative to fill multiple openings. As part of this initiative, we now invite applications for a faculty position in Materials Science to start in July 2011.

Positions are open at all levels. We seek exceptional candidates with demonstrated expertise in structure, properties, and novel synthesis of materials. Specific research interests include, but are not limited to, nanoscale and nanostructured materials, materials for advanced energy applications, materials for structural applications, mechanical properties of materials, and computational materials science.

Qualifications include a PhD or equivalent degree in Materials Science and Engineering or other relevant discipline with a strong engineering background and significant research accomplishments. Details on procedures for applying for positions at the various levels are available on the School of Engineering website at http://www.engin. brown.edu/ under 'Faculty Searches'. Applications should be received by December 31, 2010 to receive full consideration; however, the positions will remain open until filled or the search is closed.

Brown University is an Equal Opportunity Affirmative Action employer. Women and candidates who are members of minority groups are especially encouraged to apply.

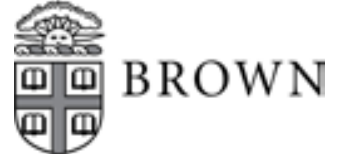




\section{Tier II Canada Research Chair}

Department of Mechanical and Manufacturing Engineering Faculty of Engineering

Located in the thriving, multicultural city of Winnipeg, the University of Manitoba offers students and faculty a vibrant learning community, exceptional facilities and the chance to explore ideas, challenge assumptions and turn theory into reality. Our researchers are among the best in the world, finding new ways to protect the environment, improve human health, advance technology and strengthen communities in Canada and beyond. With more than 30,000 students, faculty, and staff, and over 90 degree programs, the University of Manitoba plays a key role in the social, cultural, and economic well-being of our community and our world.

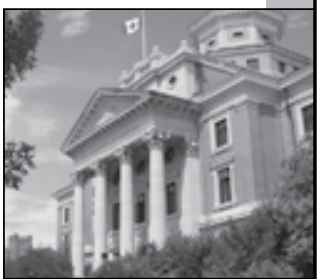

The University of Manitoba is seeking applications or nominations for a Tier II Canada Research Chair (CRC). These chairs were established by the Government of Canada to foster world class research excellence in Canadian Universities (www.chairs.gc.ca). The Chair will be expected to pursue a vigorous research program in the area of Biomedical Engineering Materials based in the Department of Mechanical and Manufacturing Engineering in the Faculty of Engineering. The program should enhance the University's existing research strength in the biomedical engineering area, and bring complementary strengths in one or more of the following areas: biocompatible materials for implants; corrosion of orthopaedic implants; failure analysis, composition, properties, and microstructure of implants; and, bio-interaction between tissue cells and implantable metals/ceramics/ polymers. The successful applicant must hold an earned doctoral degree in the field of Biomedical Engineering Materials. In addition, the individual should have an outstanding publication record that demonstrates a successful and active research program or the potential to develop an outstanding research program. The appointment will be at the Assistant Professor or Associate Professor level with reduced teaching responsibilities.

The position represents an exciting opportunity for experienced individuals who are recognized internationally as emerging leaders or as leaders in their field and who are currently seeking a tenured position, or the rank of Assistant or Associate Professor. Biomedical and Material Science are a major thrust in the University's strategic research plan and the University has allocated a total of seven NSERC CRCs to this general area of research excellence: four Tier I CRCs and three Tier II CRCs (http://umanitoba.ca/admin/vp_research/media/strategicplan_current.pdf). The University and the Department maintains one of the top materials laboratories in Canada with equipment such as a high resolution TEM, TEM, SEM, Auger electron microscope and FEI environmental SEM. The Department has strong connections with the Faculty of Medicine and the Concordia Hip and Knee Institute.

The Department of Mechanical and Manufacturing Engineering is responsible for an accredited Mechanical Engineering undergraduate program and options in Aerospace Engineering and Manufacturing Engineering. The Department is very active in graduate teaching and research at the M.Eng., M.Sc. and Ph.D. levels. Currently there is a Tier-II Canada Research Chair in Solid Mechanics and a NSERC/Manitoba Hydro Alternate Energy Industrial Research Chair, and there is an ongoing search for a Tier II Canada Research Chair in Biomedical Materials Engineering. The Department presently has 27 academic staff, 14 support staff, several post-doctoral fellows, research associates and visiting scholars, as well as approximately 120 graduate students and 380 undergraduate students.

Additional information on the Department can be found at our website

http://umanitoba.ca/faculties/engineering/departments/mechanical/index.html

Winnipeg is a mature city of some 700,000 people with rich recreational and cultural opportunities. It combines the amenities of urban life with easy access to the countryside and to northern lakes and forests. Housing prices are low by North American standards. Additional information can be found at: http://www.city.winnipeg.mb.ca/ and http://www.gov.mb.ca/

The review of applications will begin on December 1, 2010, and will continue until the position is filled. Applications should quote Search \#12119 and include a curriculum vitae, a brief five year research plan, a one-page statement of research and teaching goals as well as contact information for at least three referees. Please submit all materials to: Professor D. Kuhn, Chair of the Search Committee, Department of Mechanical and Manufacturing Engineering, University of Manitoba, Winnipeg, Manitoba, Canada R3T 5V6, www.umanitoba.ca

All e-mail enquiries should be sent to nabess@cc.umanitoba.ca to the attention of Prof. D. Kuhn.

The University of Manitoba encourages applications from qualified women and men, including members of visible minorities, Aboriginal peoples, and persons with disabilities. All qualified candidates are encouraged to apply; however, Canadians and permanent residents will be given priority.

Application materials, including cover letter, curriculum vitaes, and letters of reference, will be handled in accordance with the protection of privacy provisions of "The Freedom of Information and Protection of Privacy Act" (Manitoba) and will be provided to participating members of the search process.

For more information on this opportunity, please visit umanitoba.ca/employment

\section{One university.} Many futures.
UNIVERSITY OF MANITOBA
BOSTON

UNIVERSITY

\section{Faculty Position}

Department of Mechanical Engineering
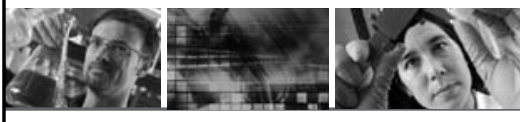

The Department of Mechanical Engineering at Boston University invites applications for a tenure-track faculty position in energyrelated areas relevant to Mechanical Engineering. Specific areas of interest include:

- Energy from sustainable sources

- Waste heat capture

- Energy storage technologies

- Computational science for energy applications

This position will likely be coupled with one or more of the following: the college-wide undergraduate Energy Technologies and Environmental Engineering concentration, the graduate university-wide Clean Energy and Environmental Sustainability Initiative, and the Energy Materials concentration in the Division of Materials Science and Engineering.

Qualified candidates at all academic ranks will be considered, however, applicants seeking appointment above the rank of assistant professor must have a distinguished record of academic and professional performance and must clearly demonstrate the ability to develop and sustain a program of graduate education in their field as well as a funded research program.

The Department of Mechanical Engineering has strong research programs in acoustics and vibrations; biomechanics; computational science and engineering; dynamics, robotics, systems and controls; thermofluid sciences, energy and sustainability; materials; and MEMS and nanotechnology. The department is further strengthened by its affiliation with the Division of Materials Science and Engineering, the Division of Systems Engineering, the Fraunhofer USA Center for Manufacturing Innovation, the Center for Information and Systems Engineering, and the Photonics Center. Both the Department and College are working to implement ambitious ten-year plans that envision substantial growth in the coming years.

For additional information and for instructions on how to apply, please go to: http://www.bu.edu/me/facultysearch

Boston University is an equal opportunity, affirmative action organization. 


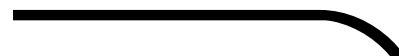

\section{Postdoctoral \& Postgraduate Positions}

Institute for Mechanics of Materials and Structures

\section{MULTISCALE MECHANICS OF BIOLOGICAL MATERIALS}

Thanks to financial support of the European Research Council (ERC-erc.europa. eu), whose mission is "to stimulate excellence by supporting the very best, truly creative scientists, scholars and engineers," the Institute for Mechanics of Materials and Structures at the Vienna University of Technology (TU Wien) invites applications to several positions at the postdoctoral as well as $\mathrm{PhD}$ student level. Candidates with strong backgrounds in engineering mechanics, biophysics, materials science, and/or applied mathematics (as proven through an internationally competitive track record) are expected to strive for excellence and to enthusiastically cross the boundaries between traditionally separated scientific disciplines, namely engineering, applied mathematics and physics, as well as the life sciences.

Situated in the very center of the charming cosmopolitan city of Vienna, worldrenowned for its scientific convention tradition and its life quality, the Vienna University of Technology is one of the oldest institutions of its kind in the world, and has, since 1815 , lived up to its motto "new technologies for the improvement of human life." Working in a culturally and scientifically most stimulating atmosphere, the successful candidates will earn internationally competitive salaries. Employment durations will vary between three and five years; extensions may be possible depending on the candidates' performance.

Review of candidates will begin December 15, 2010, until the positions are filled.

Interested candidates should send a letter of application, curriculum vitae, and names and addresses of three references to Prof. Christian Hellmich at

Christian.Hellmich@tuwien.ac.at

Tel: 43-1-58801-20220.
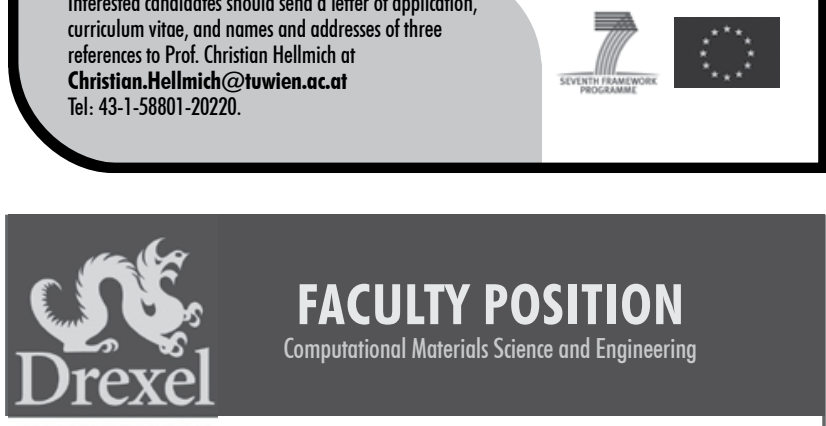

U NIVERSITY

The Department of Materials Science \& Engineering at Drexel University (www.mse.drexel.edu) is seeking applications for a tenure/ tenure-track faculty position with a demonstrated record of excellence in computational materials science and materials engineering. This position will be offered at a rank commensurate with the qualifications of the applicant. While primary consideration will be given to candidates with areas of expertise in materials for energy conversion and storage, the ideal applicant should possess research interests that are synergistic with one or more existing strengths of the department, including nanomaterials, polymers, electronic materials, biomaterials, complex oxides, materials in extreme environments, and advanced microstructural design and processing. Additional consideration will be given to applicants who have the capacity to introduce computational methods and simulation to students as a tool for guiding student learning of principles of materials science and engineering at both the undergraduate and graduate levels.

Outstanding students, an accomplished faculty, dedicated staff, and investments in infrastructure and in key instrumentation within a staffed materials characterization facility in recent years have contributed to enhancing the quality of our academic programs and the visibility of our research profile, which was recently ranked \#11 among all materials PhD programs in the US by the National Research Council. Applicants should submit a cover letter; a full curriculum vitae, statements of research and teaching plans, and three letters of recommendation online at http://www.materials.drexel.edu/faculty/positions/. Applications received by December 31, 2010 will receive full consideration.

Drexel University is an Equal Opportunity Employer and encourages applications from qualified women and minorities.

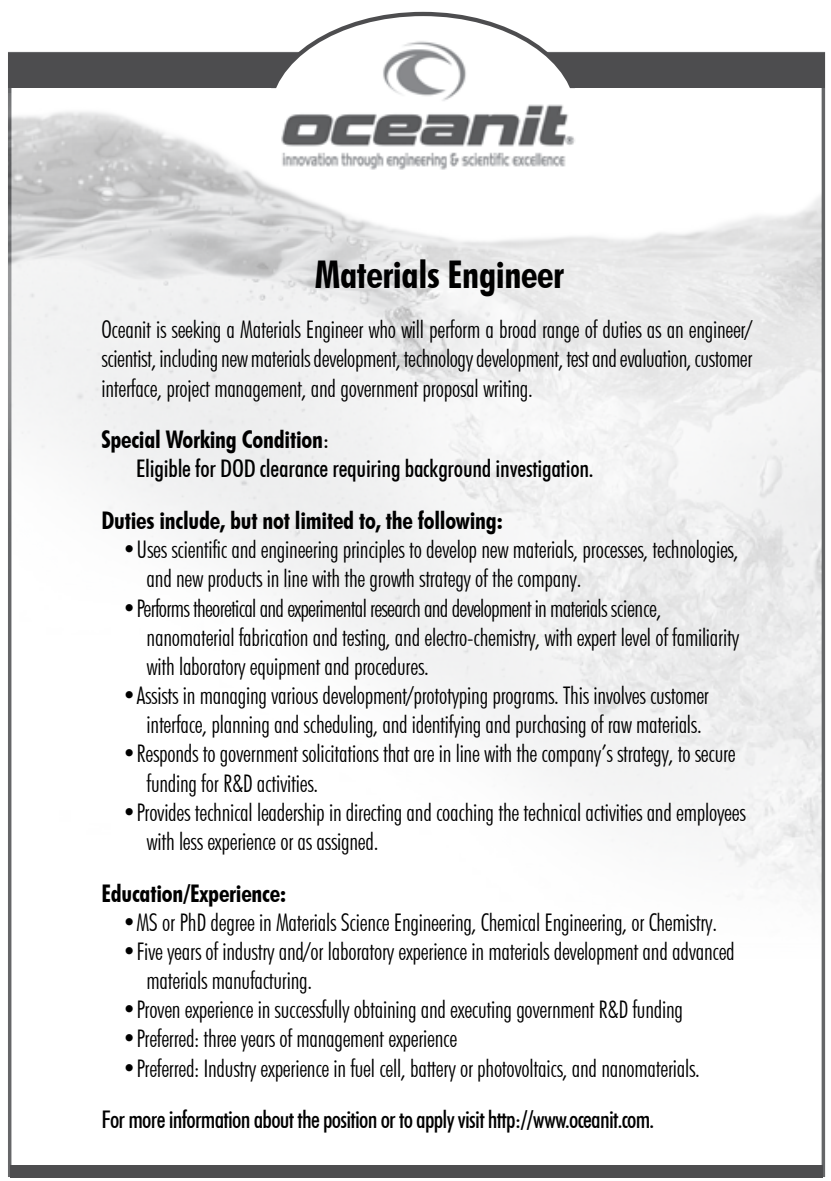

\section{Neutron Scattering Instrument Scientist}

Neutron Sciences Directorate at Oak Ridge National Laboratory invites applications for an Extended Q-Range Small-Angle Neutron Scattering (EQ-SANS) Instrument Scientist.

The successful candidate will be a team member providing operational support for the new EQ-SANS instrument at the Spallation Neutron Source and developing a vigorous scientific program associated with the instrument.

An extensive record of research accomplishments using small angle neutron and/or $x$-ray scattering is required. A Ph.D. and a minimum of two years of experience as a Research Scientist in material science, physics, chemistry, or related fields(or equivalent combination of training and experience) are also required.

For more information about the position or to apply visit:

http://jobs.ornl.gov/neutron_science.shtml

\section{neutrons.ornl.gov}

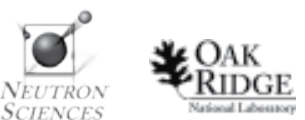

ENERGY

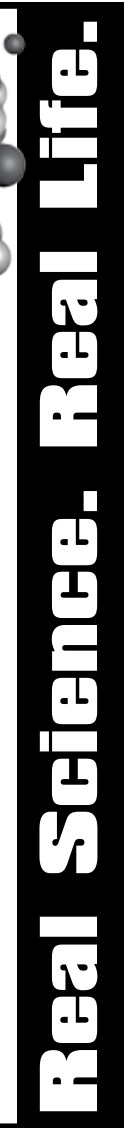

